\section{The British Cardiovascular Society annual conference, Manchester, 4-6 June 2018: the Vice President's message}

\author{
John P Greenwood ${ }^{1,2}$
}

On behalf of the President, Board, Executive and Programme Committee at the British Cardiovascular Society (BCS), we look forward to welcoming you to Manchester in June for the BCS 2018 Annual Conference.

Our theme this year is 'High Performing Teams' which opens up the possibility of exploring how, in addition to the National Health Service (NHS), non-healthcare sectors meet the daily challenges of consistently high performance, delivery to time and target, while minimising risk and complaints. With speakers from the consumer sector (Amazon), motor sport (Porsche), the armed forces (SAS and RAF) and sport (Olympians), there should be valuable lessons for us all to take away.

The conference will be opened by the President, Dr Sarah Clarke, followed by the opening lecture 'A high performing team' delivered by Dr Doug Gurr, manager of Amazon, UK (figure 1). He started his career as an academic teaching maths and computing, worked in the Civil Service, founded Blueheath, the internet enabled stockless wholesaler and was Chairman of the National Museums of Science and Industry.

THEME OF 'HIGH PERFORMING TEAMS' Regular attenders at the BCS Annual Conference will be aware that we try and deliver a range of 'something different' sessions punctuated throughout the meeting that are related to the conference theme. This year, we are delighted to have the following showcase sessions: (1) 'Leadership of those with the powers of life and death' by the Hon Charles (Chips) Broughton MBE (ex-SAS; figure 2); (2) 'Cleared for take-off!' by Mrs Mandy Hickson (former RAF Tornado pilot; figure 3) and (3) 'High performance teams-lessons learnt from motorsport

${ }^{1}$ Department of Cardiology, Leeds Teaching Hospitals NHS Trust, Leeds, UK

${ }^{2}$ Leeds Institute of Cardiovascular and Metabolic Medicine, University of Leeds, Leeds, UK

Correspondence to Professor John P Greenwood, Leeds Institute of Cardiovascular and Metabolic Medicine, University of Leeds, Leeds LS2 9JT, UK; j. greenwood@leeds.ac.uk

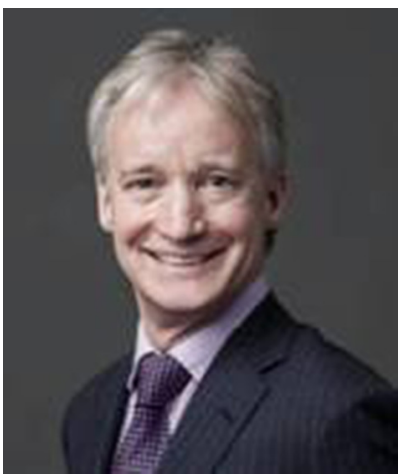

with Porsche' by Richard Tuthill (ex-world Rally Champion; figure 4).

\section{What's new for 2018?}

As usual, there is an action-packed programme that includes all of the popular subspeciality tracks, the hallmark of our conference for education and revalidation. In response to the feedback from last year's conference, new initiatives for this year include: (1) an introductory Leadership Course delivered in partnership with the internationally renowned Ashridge Business School; (2) greater access to live scanning and imaging training in the Education Zone; (3) an Innovation Zone which will encompass Med-Tech companies and Clinical Entrepreneurs presenting their innovative ideas; (4) to raise the profile of our best clinical science, the top three scoring abstracts in each abstract category will be presented orally in the Innovation Zone, with prizes for the 'Best

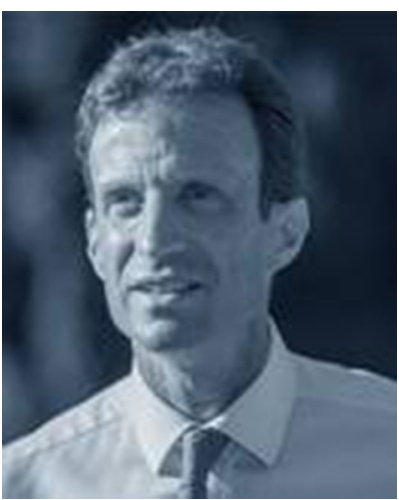

Figure 2 Hon Charles Broughton.
Figure 1 Dr Doug Gurr.

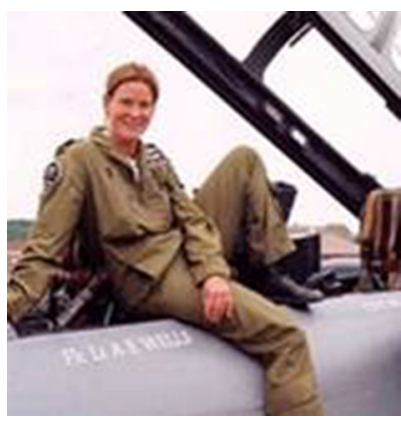

Figure 3 Mrs Mandy Hickson.

of the Best' awarded at the new Closing Ceremony; (5) a Trainees Quiz on the Monday (Trainees Day), the format of which will be educational and fun, with prizes for the highest scorers and (6) a Doctors Mess exclusively for trainees, which will provide a quiet area for fun and relaxation.

\section{NAMED LECTURES}

The Named Lectures, presented by eminent physicians and academics, are a major highlight of our conference each year. As a mark of their importance, they are unopposed by any other session in the programme. This year's Thomas Lewis lecture will be delivered by Professor Pamela Douglas entitled 'Evaluating stable chest pain patients: evolving evidence for precision testing'. Professor Pamela Douglas (figure 5) is the Ursula Geller Professor of Research in Cardiovascular Diseases in the Department of Medicine at Duke University and Director of the Multimodality Imaging Programme at Duke Clinical Research Institute. Professor Douglas has led several landmark clinical trials and has served as the President of the American College of Cardiology and President of the American Society of Echocardiography.

The BCS lecture will be delivered by Professor Martin Cowie and is entitled 'From evidence to implementation-does it need to take 20 years?' Professor Cowie (figure 6) is the Professor of Cardiology at the National Heart and Lung Institute, Imperial College, London, and Honorary Consultant Cardiologist at the Royal Brompton Hospital, London. A founding

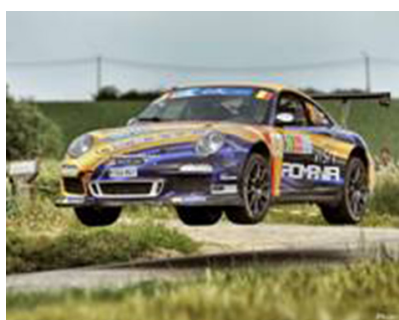

Figure 4 Richard Tuthill. 


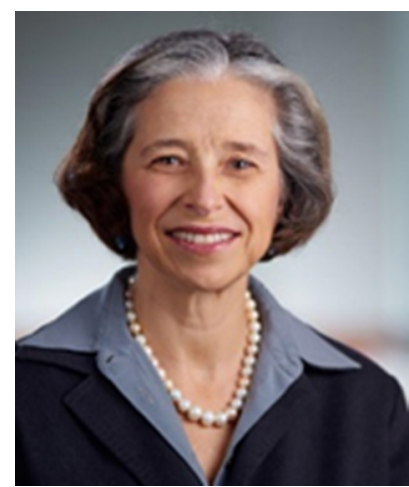

Figure 5 Prof Pamela Douglas.

member and a past chairman of the British Society for Heart Failure, Professor Cowie has also been a Board member (and Chair of the Education Committee) of the Heart Failure Association of the European Society of Cardiology (ESC).

Finally, organised by the British Society of Cardiovascular Research and the British Atherosclerosis Society, the John French lecture will be delivered by Dr Sarah De Val (Oxford) (figure 7) and is entitled 'An enhancer-based approach for studying blood vessels in development and disease'. Dr De Val gained her PhD in Genetics and did postdoc studies at the University of California's Berkeley campus and the University of California San Francisco. She now leads a research group at the Ludwig Institute for Cancer Research at the University of Oxford, where she works on gene regulation to control the growth of blood vessels into solid tumours.

\section{COLLABORATION WITH THE BRITISH HEART FOUNDATION (BHF)}

Our growing partnership with the British Heart Foundation (BHF) continues in 2018. Professor Sir Nilesh Samani, BHF Medical Director, will facilitate the 'Benchto-Bedside' session on 'New biomarkers and diagnostics for precision cardiovascular medicine'. This session will consist

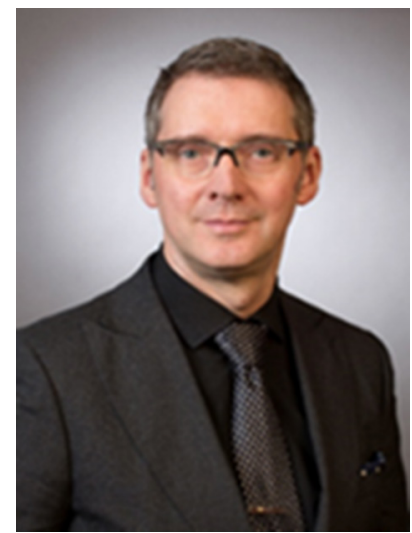

Figure 6 Prof Martin Cowie.

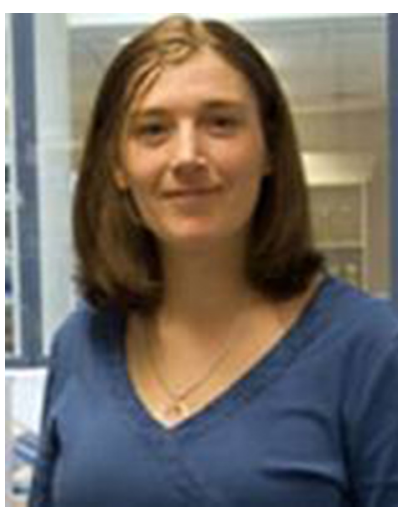

Figure 7 Dr Sarah De Val.

of four talks, focusing on potential novel diagnostic techniques, from soluble and imaging biomarkers, through to genetic and multiomic approaches. New for 2018 will be a session dedicated to BHF Fellows, spotlighting the work of some of the country's leading academic clinical scientists. Finally, there will again be a session by the BHF Alliance, an organisation that provides learning and development opportunities for healthcare professionals who work with people affected, or at risk of, cardiovascular disease.

\section{COLLABORATION WITH THE BRITISH SOCIETY OF CARDIOVASCULAR RESEARCH (BSCR) AND BRITISH ATHEROSCLEROSIS SOCIETY (BAS)}

The 'basic science track' is provided by the BSCR/BAS Spring meeting, integrated into the first 2 days of the conference. This part of the meeting is always extremely well attended and of very high quality in terms of scientific content. This year, cuttingedge sessions in cardiovascular science include (1) ageing and senescence in the cardiovascular system; (2) nanomedicine for the future diagnosis and treatment of cardiovascular disease; (3) inflammation as a link between hypertension and cardiovascular risk and (4) disease modelling in a dish. This year's translational highlight session organised jointly by the BCS, BSCR and BAS, is 'inflammation in the pathogenesis and treatment of coronary heart disease and acute coronary syndromes'.

\section{COMPREHENSIVE COVERAGE OF ALL THE NEW DEVELOPMENTS IN CARDIOLOGY AND CARDIOVASCULAR SCIENCE}

If the above was not enough to whet your appetite, then the following summary of other key conference tracks and days should be:

- National training day: including NSTEMI MDT-Live; Cardiology
SAC Session: the European Exam in General Cardiology-what trainees and trainers need to know; Trainee Quiz; trainee Hot Topics.

- Affiliated Society track: an opportunity to update your knowledge with sessions delivered by other Affiliated Societies to your own. Or if you really can't stay away, you can go to your own Affiliated Society session-you will still learn something.

- BCS 'bigh-performance' sessions: including 'serious untoward incidents-how safe is your team', getting it right first time, NHS operation structure and performance, 'digital and social media for dummies how not to get struck off', women in cardiology and insights from journal editors (Lancet, EHJ, Heart).

- Imaging track: including read with the experts, abstract poster sessions, integrated imaging content in the main sessions of the programme, multimodality practical hands on training in the Education Zone, imaging hot topics.

- Hackathon: an 'innovation multidisciplinary meeting', where specialists and young entrepreneurs gather to develop solutions to common 'pinch-points' in service delivery. If you are intrigued, then check out http://www.bcshackathon.com/what-is-the-bcs-hackathon/.

- Clinical science and translational research in the innovations in clinical cardiology track, including the Michael Davies Early Career Award.

- Basic science: the Spring Meeting of BSCR and BAS, abstract poster sessions, the John French lecture and basic science hot topics.

- Education for revalidation (E4R) sessions including 'Top 10 Trials', ECG interpretation, 'Life Long Learning' and the ever-popular 'BCS quiz'.

- Parallel 1day meetings dedicated to patients (CCP-UK), healthcare scientists (BSE, HRUK, SCST) and primary care practitioners (opened by Helen Stokes-Lampard, President of the RCGP).

- International sessions in association with the European Society of Cardiology, American College of Cardiology and Irish Cardiac Society.

Finally, I am immensely grateful and impressed by the willingness of cardiologists and cardiovascular scientists, both from the UK and internationally, to give their time and effort to the planning and delivery of this meeting. In particular, I would like to acknowledge the help and support of the British Heart Foundation and the staff, 
officers and Programme Committee of the BCS. The full programme and online booking for lifelong learning, simulators, imaging village, introductory leadership course, parallel 1 day meetings and the annual dinner are all available online at www.bcs.com/conference.

We look forward to seeing you in Manchester!
Funding The authors have not declared a specific grant for this research from any funding agency in the public, commercial or not-for-profit sectors.

Competing interests None declared.

Patient consent Not required.

Provenance and peer review Commissioned; internally peer reviewed.

(C) Article author(s) (or their employer(s) unless otherwise stated in the text of the article) 2018. All rights reserved. No commercial use is permitted unless otherwise expressly granted.

\section{A) Check for updates}

To cite Greenwood JP. Heart 2018;104:869-871.

Heart 2018;104:869-871.

doi:10.1136/heartjnl-2018-313475 